Check for updates

Cite this: Mater. Adv., 2022, 3,1804

Received 18th August 2021, Accepted 17th December 2021

DOI: 10.1039/d1ma00740h

rsc.li/materials-advances

\section{A smart functional surfactant activated conductive polymer coated on paper with ultra-sensitive humidity sensing characteristics $\dagger$}

\author{
Jonas Mahlknecht, Günter Wuzella, (D) Herfried Lammer and \\ Mohammed Khalifa (D) *
}

\begin{abstract}
Herein, surfactant-assisted PANI nanorods were synthesized via the solid-state synthesis method at different concentrations of sodium lauryl sulfate (SLS). Upon the addition of SLS, the average rod diameter of PANI decreased from $72 \pm 6 \mathrm{~nm}$ to $58 \pm 6 \mathrm{~nm}$. The electrical conductivity of PANI increased three-fold upon the addition of SLS $\left(8.2 \mathrm{~S} \mathrm{~cm}^{-1}\right)$. Furthermore, the presence of SLS modulated the PANI chains, which facilitated the enhancement of the thermal stability. A PANI/SLS-based humidity sensor was built on a paper substrate through the doctor blade coating technique and its performance metrics were accessed under different humidity conditions. The PANI/SLS coated paper-based humidity sensor exhibited excellent response along with fast response/recovery characteristics. SLS assisted PANI nanorods having an improved electrical conductivity and high surface area readily interacted with water molecules, which significantly increased the sensitivity of the sensor up to $31.5 \mathrm{k} \Omega / \% \mathrm{RH}$ (linearity = 0.99). Furthermore, the sensor showed excellent response under physiological conditions such as respiration monitoring and skin moisture detection. The ultrasensitive humidity sensing performance of PANI/SLS coated paper with good skin-friendly characteristics makes it a potential material for multipurpose smart wearable devices.
\end{abstract}

\section{Introduction}

Humidity sensing is essential to monitor, detect and control the conditions related to food storage, electronic devices, medical industries and wearable devices appropriate for physiological conditions in our daily life. Recently, humidity sensors showed tremendous potential in wearable devices for respiration monitoring and body moisture detection. ${ }^{1-3}$ Humidity sensors should possess high sensitivity, fast response and recovery, high selectivity, stability, and low cost with simple design and installation to meet the requirements for different applications. Various materials, including metal oxides, semiconductors, polymers, and their composites, have been explored as active materials for humidity sensors to achieve the requirements. ${ }^{4}$ Different measurement principles such as capacitance, impedance, resistance, voltage, and dielectric constant have been adopted to read out the humidity sensor output. $^{5,6}$ Graphene-based humidity sensors demonstrated tremendous potential for humidity sensing. However, graphene

Competence Center for Wood Composites and Wood Chemistry, Altenberger Strasse 69, A-4040 Linz, Austria.E-mail: mohammed.khalifa89@gmail.com

$\dagger$ Electronic supplementary information (ESI) available. See DOI: 10.1039/ d1ma00740h often struggles to recover fast due to its poor desorption characteristics and high susceptibility to temperature change, thus hindering its practical implementation. ${ }^{7,8}$ Recently, flexible humidity sensors with good electrical properties have become a central focus due to their light weight, easy handling and the fact that they can be attached to various complex parts. Polymer-based humidity sensors with an affinity for water molecules from hydrophilic functional groups are seen as the most feasible humidity sensors due to their high flexibility, low cost, and high mechanical stability. ${ }^{9-11}$

Conducting polymers, especially polyaniline (PANI), have received significant attention due to their inexpensive monomer, ease of preparation, high yield and environmental stability. ${ }^{12,13}$ PANI has shown great potential in applications such as electronics, corrosion protection layers, chemical sensors, anti-microbial coatings etc. ${ }^{14}$ The electrical properties of PANI can be modulated by changing its oxidation state and protonation of the amine group since the electrical conductivity of PANI depends on the mobility of charge carriers and the hopping mechanism between the PANI chains along with the concentration of charge carriers. Hence, water molecules could alter the charge mobility, thereby fluctuating its electrical conductivity, which makes it an active material for humidity sensors. ${ }^{15-17}$ Despite the several feasible characteristics, PANI 
has limited its practical application due to its poor mechanical strength, solubility and sensing response characteristics. ${ }^{18}$ To encounter this, PANI is often used in the form of blends, composites and doped forms. Tungsten disulfide, ${ }^{19}$ titanium dioxide, ${ }^{20}$ silver, $^{21}$ zinc oxide, ${ }^{22}$ nickel oxide, ${ }^{23}$ poly(vinyl alcohol), ${ }^{11}$ chitin $^{24}$ etc. have been used with PANI to tune the physical and chemical properties and to enhance the humidity sensing performance. On the other hand, surfactants and dyes including sodium lauryl sulfate (SLS), cetyltrimethylammonium bromide, ${ }^{25}$ dodecylbenzenesulfonic acid, ${ }^{26}$ Triton $\mathrm{X}-100,{ }^{27}$ orange dye ${ }^{28}$ etc., have been used as doping agents to enhance the electrical conductivity and tune the morphology of PANI. SLS doped PANI increased the electrical properties by $200 \%$ compared with pure PANI. ${ }^{29}$ Hydrophobically end-capped poly(ethylene oxide) was used as a polymer surfactant to tune the morphology and crystallinity of PANI. Polymerization of aniline monomers occurs at the micelle-water interface and the surfactant acts as a steric stabilizer. ${ }^{30}$ Triton X-100 surfactant-assisted PANI prepared without shaking or stirring showed homogenous and consistent PANI nanofibers along with increased electrical conductivity. ${ }^{27}$ An orange dye-doped PANI-based impedance sensor in the relative humidity range of $30-90 \%$ showed a uniform impedance-humidity relationship. Furthermore, annealed samples showed an increase in the sensitivity. ${ }^{31}$ However, the low electrical conductivity and reversible humidity sensing effect of PANI under high humidity conditions hindered its practical use. Also, PANI sensors display poor reproducibility and stability upon repeated exposure to humidity. ${ }^{32}$

Despite several studies on the surfactant doped PANI, there are no reports to our best knowledge in which the effects of surfactants on the humidity sensing characteristics of PANI have been investigated. Among various surfactants, an anionic surfactant such as SLS can tune the morphology, electrical properties and crystallinity of PANI, which could be beneficial for humidity sensor performance. ${ }^{33,34}$ Due to the brittle characteristics of PANI, it is difficult to prepare it in the form of thin films. Furthermore, coating PANI on ceramic substrates is expensive and requires a high precision process. $^{35,36}$ In addition, the flexibility of PANI based sensors is rather crucial for practical implementation especially for wearable devices. Hence, highly porous cellulose paper could be a better alternative to ceramic based substrates. Paper is readily available, and has several advantages, including low-cost, light weight, chemically stable, high porosity, flexible, easy installation and handling. ${ }^{37,38}$ On the other hand, application of thin films on paper substrates using the doctor blade technique is rather a simple and inexpensive process, which is suitable for large scale production. ${ }^{39,40}$ The flexibility and porosity of paper and good humidity sensing capabilities of PANI with a facile process could make it a potential material for wearable electronics. Also, use of screen printed electrodes on the paper prevents any kind of disruption in the resistance signals.

With the above motivation, we have synthesized SLS-assisted PANI (PANI/SLS- $X$ ) via a solid-state synthesis method and subsequently applied it in developing a highly sensitive humidity sensor. Furthermore, a detailed investigation has been carried out to probe the effect of SLS loading on the PANI's morphology, electrical properties and thermal stability. Besides, the chemical interaction between SLS and PANI was also studied. Finally, a PANI/SLS- $X$ coated paper-based humidity sensor was developed and its in detail performance characteristics were investigated. Furthermore, the sensor was integrated within the wearable mask to monitor human respiration.

\section{Materials and methods}

\subsection{Chemicals used}

Aniline, hydrochloric acid ( $\mathrm{HCl}$, fuming/concentrated) and ammonium persulfate (APS) were purchased from Roth Chemicals (Germany). SLS with a purity of $>99 \%$ was purchased from Sigma-Aldrich (Austria). All the chemicals were used as received without further purification.

\subsection{Preparation of SLS assisted-PANI}

PANI was synthesised in an ice-cooled porcelain mortar containing $3 \mathrm{ml}$ of $\mathrm{HCl}$ followed by the dropwise addition of $3 \mathrm{ml}$ of aniline. After slowly stirring the reactants for a minute, the remaining chemicals were added (SLS and APS (5.71 g, 0.4 M) in the given order) until the mixture turned into a thick white paste. Constant stirring resulted in the mixture turning into a dark green color paste. A green precipitate was collected from the mortar and washed several times with ethanol and deionized water until the solution became colorless and the $\mathrm{pH}$ value turns neutral. The wet product was placed in a Petri dish and dried in an oven at $60{ }^{\circ} \mathrm{C}$ for $12 \mathrm{~h}$. The final product of PANI/SLS was collected as a fine powder. This process was carried out several times for each of the six different variants of synthesized PANI, using a varying amount of SLS $(0,0.125,0.25$, 0.5 , and $0.75 \mathrm{~g}$ ).

The terminology used in this study is “PANI/SLS- $X$," where $X$ may be $0,0.125,0.25,0.5$, and $0.75 \mathrm{~g}$ of SLS used during the synthesis of PANI nanorods.

\subsection{Characterization techniques}

Fourier-transform infrared (FTIR) spectroscopy (Bruker Tensor 27 , Germany) was used to record the spectra of PANI/SLS- $X$ nanorods. Analysis was carried out in the ATR-mode in the wavenumber range of $4000-600 \mathrm{~cm}^{-1}$ at a spectral resolution of $4 \mathrm{~cm}^{-1}$. Differential scanning calorimetry (DSC) (822e-Mettler Toledo, USA.) was used to confirm PANI formation and its thermal characteristics. The test was carried out in the temperature range of $25-350{ }^{\circ} \mathrm{C}$ at a heating rate of $10{ }^{\circ} \mathrm{C} \mathrm{min}^{-1}$. Thermogravimetric analysis (TGA) (Q5000 TA instruments, USA) was carried out to study the thermal characteristics of PANI/SLS nanorods in the temperature range of $25-800{ }^{\circ} \mathrm{C}$ at a heating rate of $10{ }^{\circ} \mathrm{C} \mathrm{min}^{-1}$. The electrical properties of PANI/ SLS nanorods were studied using a four-probe conductivity meter (Ossila Instruments, UK). The sample pellets were prepared using a pellet-pressing machine. The distance between the probes was kept at $2 \mathrm{~mm}$ during the test. 
The resistivity of PANI/SLS nanorods was determined using eqn (1).

$$
\rho=2 a \pi s \frac{V}{I}
$$

where $V=$ voltage $(\mathrm{mV}), I=$ current $(\mathrm{mA}), a=$ thickness correction factor and $s=$ the distance between the probes. The thickness correction factor is given by:

$$
a=K\left(\frac{t}{s}\right)^{m}
$$

where $K$ is the correction factor based on the ratio of probe spacing to the diameter of the specimen, $m$ is the slope, $t$ is the thickness of the pellet, and $s$ is the distance between the probes.

High-resolution transmission electron microscopy (HRTEM) (Jeol/JEM 2100, Japan) was carried out to study the morphological properties of PANI/SLS- $X$ nanorods. For HRTEM analysis, PANI/ SLS- $X$ was dispersed in ethanol using an ultrasonication process for $2 \mathrm{~h}$ at $20{ }^{\circ} \mathrm{C}$. The dispersion was directly coated onto a carboncoated copper grid followed by drying in the oven for $12 \mathrm{~h}$ at $50{ }^{\circ} \mathrm{C}$. Energy-dispersive X-ray spectroscopy (EDS) was carried out to study the morphology and elemental composition of PANI/SLS- $X$.

\subsection{Fabrication of a polyaniline-coated paper sensor}

PANI/SLS- $X$ nanorods were coated onto a highly porous cellulose paper. A mixture of polyethylene glycol and PANI/SLS nanorods were prepared in deionized water. PANI/SLS- $X$ nanorods and polyethylene glycol were mixed in a ratio of $4: 1$. Polyethylene glycol was used as a binder for PANI nanorods. Subsequently, the mixture was coated onto highly porous paper and dried at $40{ }^{\circ} \mathrm{C}$. The resultant coating was in the form of a thin film of size $30 \mathrm{~mm} \times 15 \mathrm{~mm} \times 0.1 \mathrm{~mm}$. Interdigitated silver electrodes were printed on the cellulose paper beneath the coating. The sensor was connected to a digital resistance meter (Benning Electronics,
Austria) through highly conductive silver wires. A schematic illustration of the humidity sensing setup is shown in Fig. 1.

\section{Results and discussion}

\subsection{Morphological studies}

Fig. 2a shows the HRTEM image of pure PANI prepared via the solid-state synthesis method. A typical short PANI nanorod morphology was observed, commonly achieved using $\mathrm{HCl}$ as a doping agent. The average diameter of the nanorods was $72 \pm$ $8 \mathrm{~nm}$ and the average nanorod length was $\sim 290 \mathrm{~nm}$. Under high acidic conditions, the acid-base reaction that occurs with the aniline molecules leads to the formation of anilinium micelles. It is a well-known fact that the $\mathrm{HCl}$ concentration plays a vital role in forming the homogenous PANI nanorod-like morphology. Use of an equal ratio of $\mathrm{HCl}$ and aniline facilitates the transformation of the aniline monomers into anilium micelles. These micelles convert from spherical particles to a rod-like structure in the presence of $\mathrm{Cl}^{-}$ions due to electrostatic reactions between the chlorine anion and quinoid imine and the interaction between benzenoid imine and water present in the dopant. The rod-like morphology with nano dimensions is highly desirable for humidity sensing as humidity sensing involves high surface interactions with water molecules. ${ }^{34,41-43}$

Upon the inclusion of SLS, a noticeable change in the morphology was observed. A branched PANI nanorod morphology was observed upon the addition of SLS (Fig. 2b). On the other hand, the rod diameter decreased (ARD: $58 \pm 6 \mathrm{~nm}$ ) when compared with the pure PANI nanorods. Also, the length of the rod increased to $\sim 560 \mathrm{~nm}$, which provides excellent surface area. Upon a further increase in the SLS loading, nanorods with rough surfaces were formed, indicating the secondary growth of PANI (Fig. 2c). For PANI/SLS-0.75, ARD increased to $121 \pm 21 \mathrm{~nm}$ and the rod length increased to $910 \pm 77 \mathrm{~nm}$. The high loading of SLS

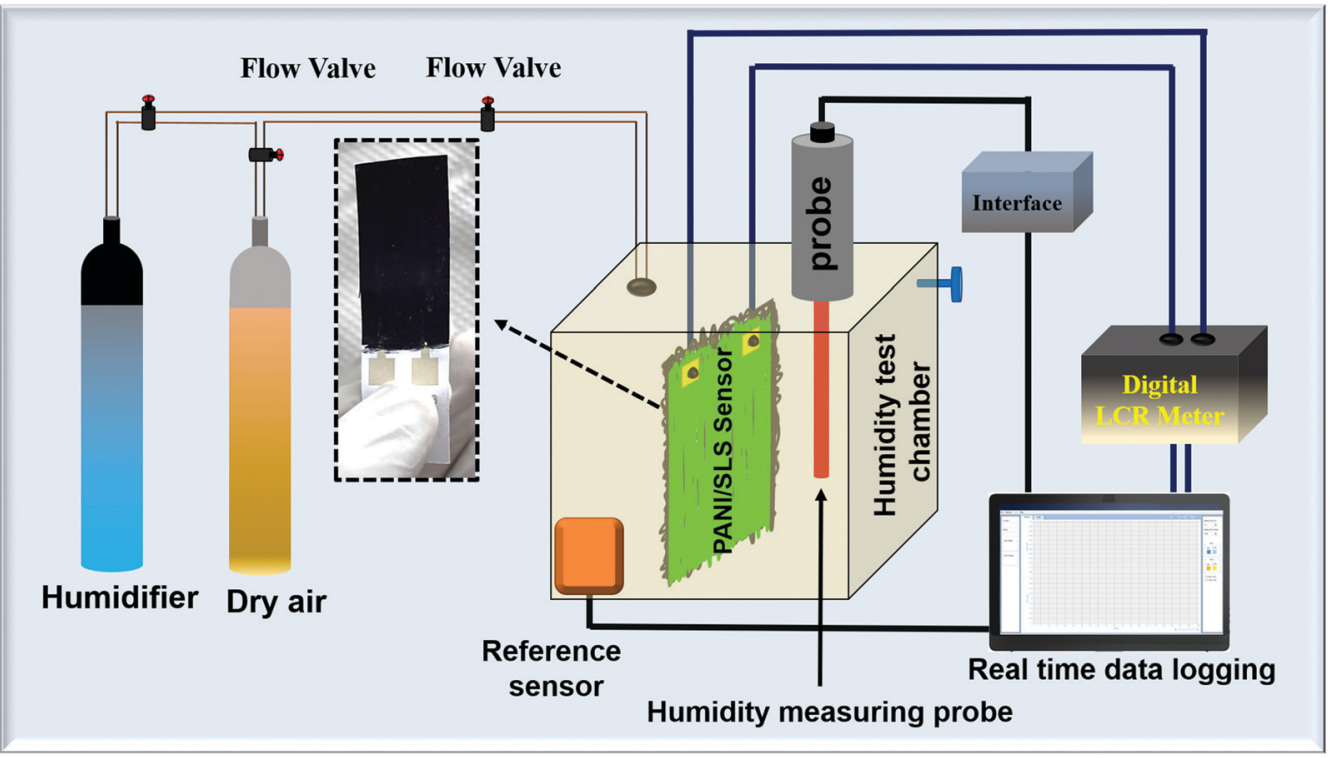

Fig. 1 Schematic illustration of the setup used for the evaluation of humidity performance. 

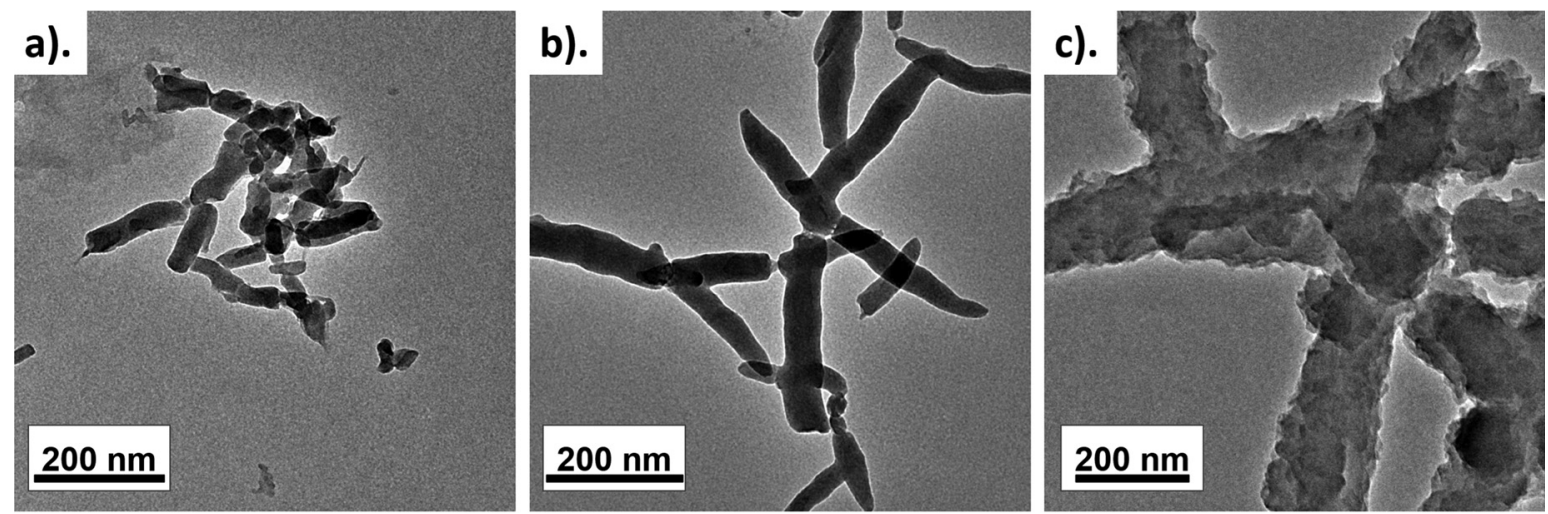

Fig. 2 HRTEM images of (a) PANI/SLS-0.0; (b) PANI/SLS-0.25; and (c) PANI/SLS-0.75

promoted heterogeneous growth, promoting the formation of a thick rod-like morphology and agglomerated structure. ${ }^{44-46}$

Table 1 shows the elemental composition of PANI/SLS-0.0 and PANI/SLS-0.25. Elements including carbon, nitrogen and oxygen were observed, which are considered to be the key elements of interest of PANI. In the presence of SLS, the nitrogen composition decreased while the oxygen and carbon compositions increased. Furthermore, trace amounts of chlorine and sulfur were detected, attributed to the byproduct of APS and HCl. Interestingly, the total yield increased with the addition of SLS. The highest yield of $56.2 \%$ was achieved for PANI nanorods loaded with $0.25 \mathrm{~g}$ of SLS.

SLS has a longer alkyl chain, which has a better solubilization effect that readily provides a platform for aniline molecules to grow into a 1D nanostructure (Fig. 3). Furthermore, the SLS molecules can stabilize the polyaniline nanostructure. On the other hand, with the hydrogen bonding interaction between the oxygen atom of SLS and the PANI nanorods, SLS molecules get easily attached to the surface of the PANI nanorods. The presence of SLS molecules on the surface of the PANI nanorods may further stabilize the nanostructure. ${ }^{33,47}$

\subsection{FTIR analysis}

Fig. 4a shows the FTIR spectra of PANI/SLS- $X$ at different loadings of SLS. Bands arising at 1563 and $1482 \mathrm{~cm}^{-1}$, respectively, assigned to the $\mathrm{C}=\mathrm{C}$ stretching of quinoid and benzenoid rings, which can be used to quantify the oxidization state of PANI. The band at $1373 \mathrm{~cm}^{-1}$, a typical signature band for the emeraldine base PANI, corresponds to $\mathrm{C}-\mathrm{N}$ stretching vibration. The band at $1292 \mathrm{~cm}^{-1}$ corresponds to the $\pi$-electron delocalization induced in the PANI chains due to protonation. Also, the band arising at

Table 1 Elemental composition (wt\%) of PANI and PANI/SLS-X at different loadings of SLS

\begin{tabular}{lllllll}
\hline Sample & $C(\%)$ & $N(\%)$ & $O(\%)$ & $\mathrm{Cl}(\%)$ & $S(\%)$ & Yield $(\%)$ \\
\hline PANI/SLS-0 & 51.6 & 28.5 & 15.1 & 1.8 & 0.8 & 48.5 \\
PANI/SLS-0.125 & 48.3 & 21 & 20.1 & 2.8 & 1.71 & 54.1 \\
PANI/SLS-0.25 & 51.4 & 14.2 & 20.9 & 4.3 & 2.1 & 56.2 \\
PANI/SLS-0.50 & 49.1 & 16.5 & 19.1 & 4.5 & 2.9 & 50.6 \\
PANI/SLS-0.75 & 54.2 & 20 & 19.8 & 4.1 & 3.3 & 44.2
\end{tabular}

$1237 \mathrm{~cm}^{-1}$ is ascribed to the characteristic of the protonated PANI and relates to the $\mathrm{C}-\mathrm{N}$ stretching vibration. A broadband at $\sim 1145 \mathrm{~cm}^{-1}$ was assigned to the $-\mathrm{NH}^{+}$vibration mode, attributed to the charged polymer units $\left(\mathrm{Q}=\mathrm{NH}^{+}-\mathrm{B}\right.$ or $\mathrm{B}-\mathrm{NH}^{+}-$ $\mathrm{B}$ ). The presence of a band at $1145 \mathrm{~cm}^{-1}$ indicates the presence of positive charges on the PANI chain and the distribution of dihedral angle between the quinoid nad benzenoid rings. The band absorption at $1145 \mathrm{~cm}^{-1}$ increased with the addition of SLS indicates the increase in the protonation level of the PANI chains. Also, the band at $1030 \mathrm{~cm}^{-1}$ corresponding to the symmetric $\mathrm{SO}^{-}$stretching on a sulfonated aromatic ring contributes to the protonation level of PANI chains. The band at $\sim 880 \mathrm{~cm}^{-1}$ indicates the protonated form of PANI. This band intensity was pronounced upon the addition of SLS. The band arising at $780-795 \mathrm{~cm}^{-1}$ may be ascribed to the higher form of polaronic delocalization of the PANI nanorods with a larger molar ratio. From the FTIR spectrum, it is apparent that the characteristic bands are ascribed to PANI. Similar bands were observed for the surfactant assisted PANI nanorods. Upon the addition of SLS, the position of the characteristics bands of PANI shifted slightly. The shift in the band position includes $1563 \mathrm{~cm}^{-1}$ to $1555 \mathrm{~cm}^{-1}$; 1482 to $1476 \mathrm{~cm}^{-1} ; 1292$ to 1288 and 795 to $784 \mathrm{~cm}^{-1}$. Also, the band at $3221 \mathrm{~cm}^{-1}$ corresponds to the $\mathrm{N}-\mathrm{H}$ stretching vibration shifted to a lower wavenumber, suggesting a strong interaction of PANI chains with the SLS molecules (Fig. 4b). ${ }^{48-50}$ The intensity ratio of bands at 1563 and $1482 \mathrm{~cm}^{-1}$ indicates the degree of the oxidation state, which helps in predicting the electrical properties of PANI. The intensity ratio was determined by deconvoluting the bands. The intensity ratio values were 0.66 for PANI/SLS-0.0, which increased to $0.79,0.9,0.86,0.75$ and 0.7 for $0.125,0.25,0.50$ and $0.75 \mathrm{~g}$ of SLS loaded PANI nanorods, respectively. The value of the intensity ratio less than 1 suggests that there are more benzene rings in the PANI chain. An intensity ratio value of 1.0 indicates that PANI can have higher electrical conductivity. ${ }^{51,52}$ From the above values, it can be predicted that PANI/SLS-025 could possess high electrical conductivity.

\subsection{TGA and DSC analysis}

Fig. 5a shows the TGA curves of PANI/SLS- $X$ at different SLS loadings in the temperature range of 25 to $900{ }^{\circ} \mathrm{C}$. The weight 
Aniline + APS + $\mathrm{HCl}$

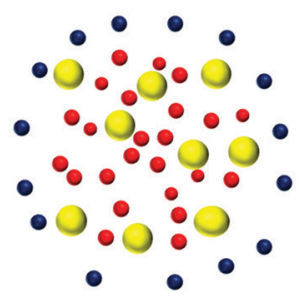

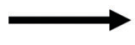

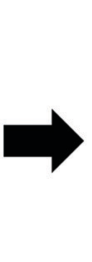

PANI nanorods

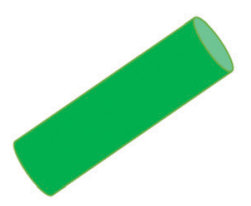

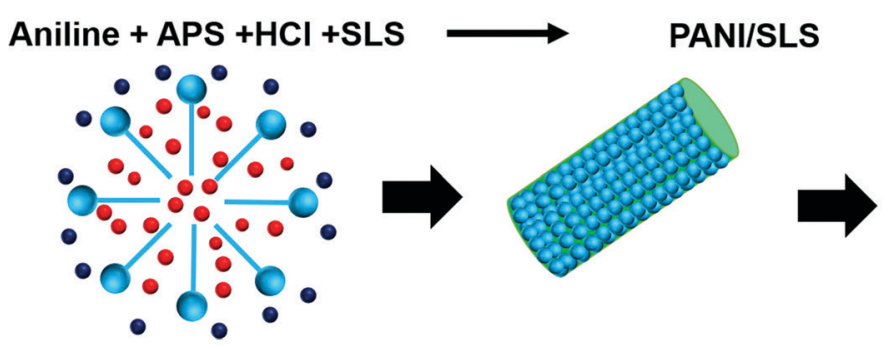

- Aniline

- APS

SLS

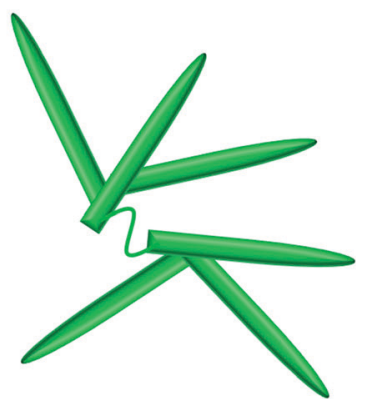

$\mathrm{HCl}$

Fig. 3 Schematic illustration of the synthesis mechanism of PANI nanorods in the presence of SLS.
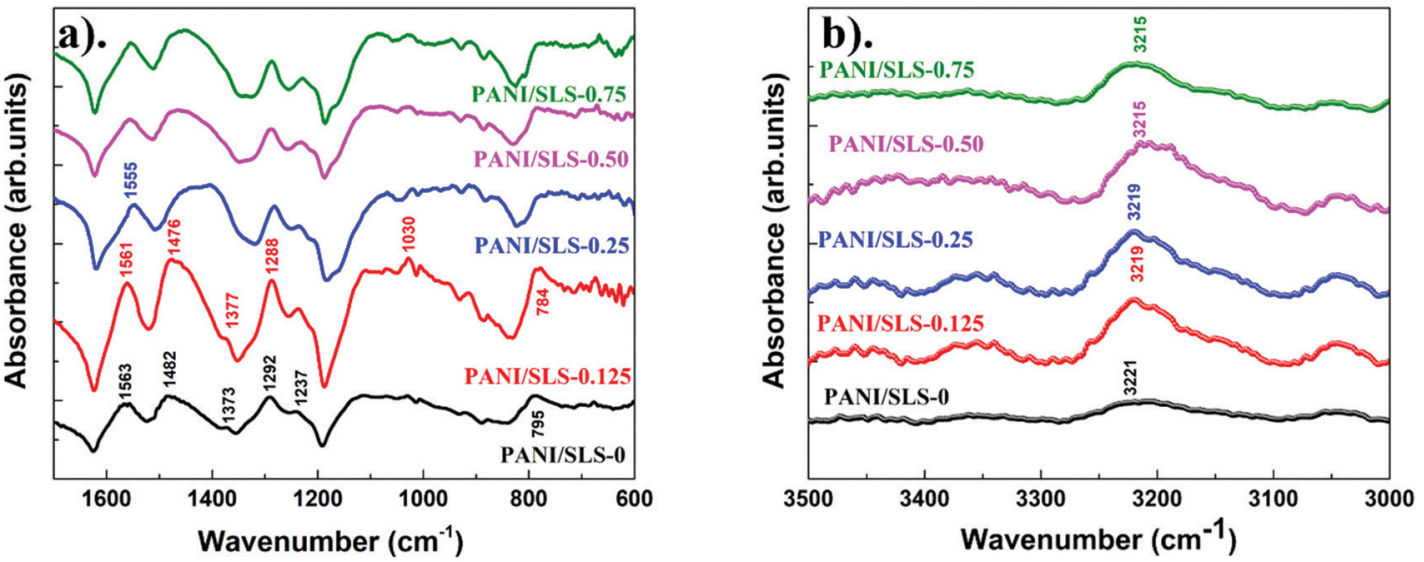

Fig. 4 FTIR spectra of (a) PANI/SLS-X at different loadings of SLS in the wavenumber range of $1800-600 \mathrm{~cm}^{-1}$; (b) FTIR spectra in the wavenumber range of $3500-3000 \mathrm{~cm}^{-1}$ illustrating the band shift related to $\mathrm{N}-\mathrm{H}$ stretching vibration.

loss of the product took place mainly in three stages. First, initial weight loss $(10 \%)$ initiated around $90{ }^{\circ} \mathrm{C}$, which could be ascribed to loss of moisture absorbed in the PANI followed by the loss due to unreacted monomers that continued up to $\sim 200{ }^{\circ} \mathrm{C}$. The weight loss could also be attributed to the uninteracted SLS particles, which can be removed easily by thermal treatment. The second significant weight loss $(40 \%)$ took place in the temperature range of $200-450{ }^{\circ} \mathrm{C}$, which can be associated with the initiation of PANI chains break into small aromatic fragments. Also, the weight loss could be associated with the water-linked PANI structure, which acts as a secondary dopant. Finally, further weight loss is due to the complete elimination and decarboxylation of aromatic fragments along with the release of $\mathrm{CO}_{2}$, decomposition of aromatic fragments and graphitization above $650{ }^{\circ} \mathrm{C}$. It is noteworthy that PANI degradation was delayed upon increasing the SLS loading. Fascinatingly, PANI/SLS-0.50 and PANI/SLS-0.75 show a maximum of $60 \%$ weight loss even after $900{ }^{\circ} \mathrm{C}$. In the initial stages, the weight loss at low temperature was significant in PANI when loaded with SLS, while in the latter stage, the degradation temperature increased. Therefore, the addition of SLS apparently blocked the thermal transition at elevated temperatures. Also, the presence of more benzenoid rings than the quinoid ring in surfactant assisted PANI nanorods improved the thermal stability. Furthermore, SLS has a symmetric double bond in its structure $(\mathrm{O}=\mathrm{S}=\mathrm{O})$ might have facilitated the improvement of the thermal stability. A similar enhancement in the thermal stability was reported elsewhere. ${ }^{53,54}$ However, the exact mechanism for thermal stability enhancement is still unclear. 

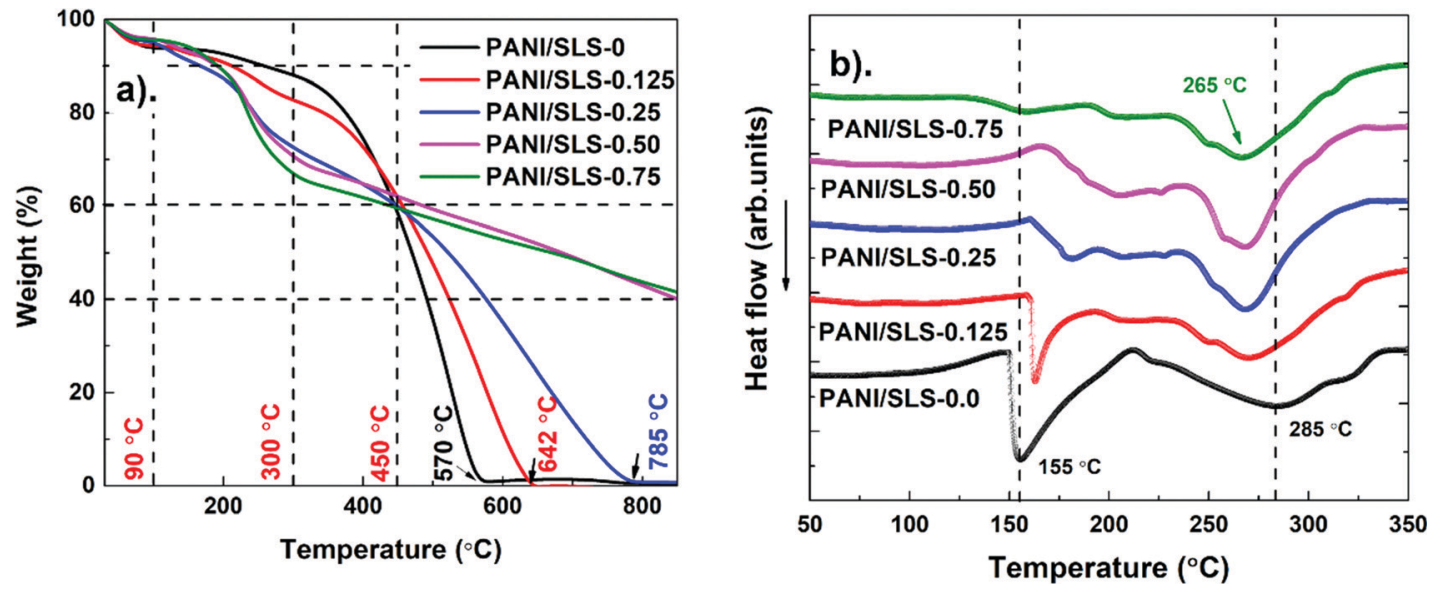

Fig. 5 PANI/SLS- $X$ at different SLS loadings. (a) TGA curves and (b) DSC curves.

Fig. 5b shows DSC curves of PANI/SLS- $X$ at different SLS loadings. An intense endothermic peak around $\sim 150{ }^{\circ} \mathrm{C}$ was observed for pure PANI associated with the evaporation of moisture, which was also evident from TGA. A broad endothermic peak, which initiates at $200{ }^{\circ} \mathrm{C}$, goes up to $340{ }^{\circ} \mathrm{C}$. The peak arising at $\sim 240{ }^{\circ} \mathrm{C}$ is ascribed to the elimination of water linked to the PANI chain as a secondary dopant. The peak at $285{ }^{\circ} \mathrm{C}$ could be attributed to the loss of the dopant, which weakened upon the addition of SLS. Above $300{ }^{\circ} \mathrm{C}$, the endothermic process is ascribed to the initiation of chain scission of PANI chains into small aromatic fragments. These results are in line with the TGA results. ${ }^{55-57}$

\subsection{Electrical properties}

Fig. 6a shows the $I-V$ characteristics of PANI/SLS- $X$ at different loadings of SLS. All curves show a linear trend suggesting that the electrical conductivity of PANI/SLS- $X$ shows Ohmic behavior. Upon the application of an electric field, the formation of charges rises significantly, which contributes to an increase in electric voltage while gradually increasing the current. The results clearly indicated that as the SLS content increased, the electrical conductivity of PANI was found to increase
(Fig. 6b). However, after reaching the maximum electrical conductivity with optimum SLS loading, with a further increase in the SLS loading, a drastic decrease in the electrical conductivity was observed. The decrease in the electrical conductivity at higher loading of SLS could be attributed to the restrictions of the carrier transport between the adjacent conjugated chains of PANI. The highest electrical conductivity was obtained for PANISLS-0.25, which is thrice the electrical conductivity of pure PANI nanorods. The above results indicate that the SLS assisted PANI showed higher electrical conductivity, which could be attributed to the increase in the ionic strength upon the inclusion of SLS as a donor ionic agent. Furthermore, the crystallinity and decrease in PANI nanorod size upon the inclusion of SLS might have contributed to the enhancement of electrical conductivity. Overall, SLS effectively acted as a protonation agent, which leads to an increase in the electrical properties of PANI by forming an anilium/SLS compound..$^{29,58-60}$

\subsection{Humidity sensing}

For humidity sensing, the sensor was kept in a glass-sealed test chamber. The relative humidity inside the chamber was maintained using a dry and moist air inflow, controlled by
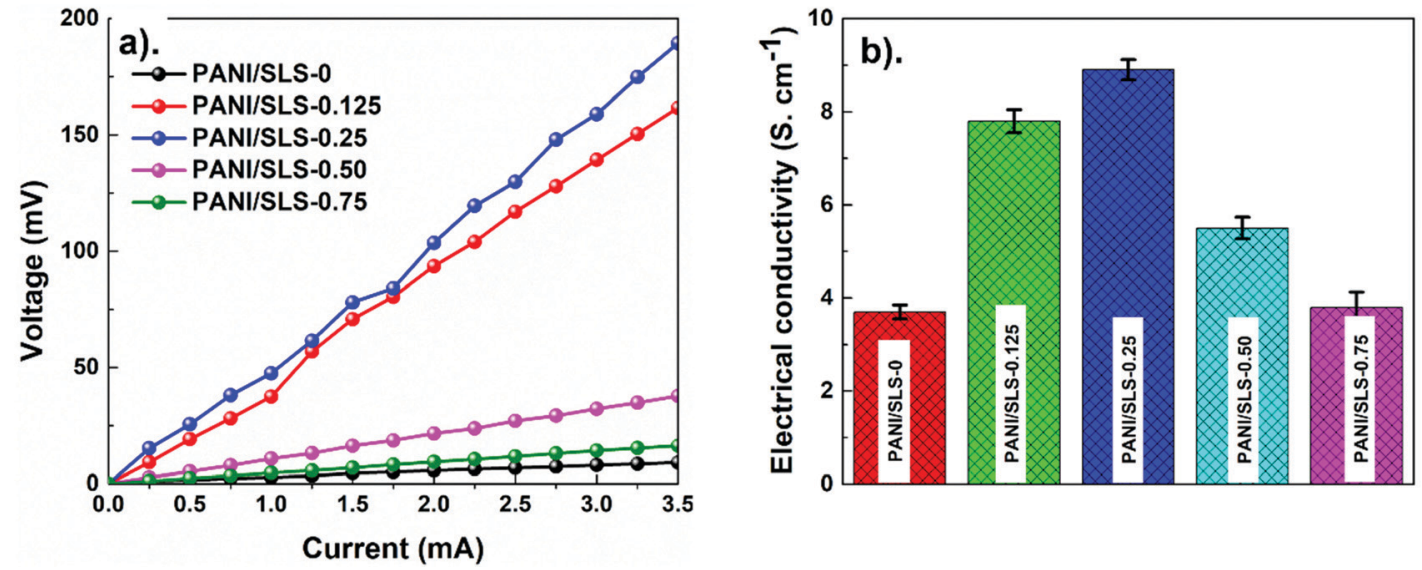

Fig. 6 PANI/SLS- $X$ at different SLS loadings. (a) $V-I$ characteristics; (b) electrical conductivity. 
two valves. The relative humidity was monitored using a highprecision humidity tester (Testo $176 \mathrm{H} 1$, Austria). The response and recovery of the sensor were recorded using a digital resistance meter, which was connected to a computer. The response of the sensor was taken as $R \%$ and calculated as follows:

$$
\% R=\frac{R_{\mathrm{i}}-R_{\mathrm{f}}}{R_{\mathrm{i}}} \times 100=\frac{\Delta R}{R_{\mathrm{i}}} \times 100
$$

Here, $R_{\mathrm{i}}$ and $R_{\mathrm{f}}$ are the resistance of the sensor under initial and moist conditions, respectively, and change in the electrical resistance of the sensor $(\Delta R)$ is taken as the difference between $R_{\mathrm{i}}$ and $R_{\mathrm{f}}$. The sensitivity of the sensor was determined using the slope of the response curve under different humidity conditions.

Fig. 7a shows the dynamic change in the sensor (PANI/SLS-0.25) electrical resistance as a function of relative humidity (5-90\%) at $23{ }^{\circ} \mathrm{C}$. The electrical resistance of the sensor decreased with the increase in the relative humidity values. Note that the sensor response was stable at a humidity level above $10 \%$, while at $<10 \%$, the response of the sensor was ambiguous. The decrease in the electrical resistance with an increase in relative humidity indicates the p-type semiconducting behavior of the sensor. Besides, the sensor was also investigated for its hysteresis characteristics. The humidity was increased from $5 \%$ to $90 \%$ and then reduced stepwise back to $9 \%$ to investigate the adsorption and desorption characteristics. The desorption curve was slightly delayed compared with the adsorption curve, which could be attributed to the slower recovery of the sensor. However, the difference in the adsorption and desorption curves was insignificant. The adsorption and desorption curves coincide within an error of $\pm 1.5 \%$. The repeatability and responserecovery time of the sensor were also evaluated by varying the humidity between $32 \%$ and $65 \%$ (Fig. $7 \mathrm{~b}$ ).

Interestingly, the resistance of the sensor promptly responded with the variation in the humidity conditions. The response time of the sensor was estimated as $18 \mathrm{~s}$, while the recovery time was $\sim 35 \mathrm{~s}$. The recovery of the sensor from the high humidity level to low humidity level is sluggish. The response and recovery time of the sensor are illustrated in Fig. S1 (ESI $\dagger$ ). The phenomenon could suggest that water molecules penetrated in the PANI chains and held tightly between the intervenes of the cellulose fibers (paper substrate). A more significant number of water molecules are absorbed under high humidity conditions, making it difficult to remove from the sensor's surface. The cyclic test of the sensor exhibited the response and recovery curve, suggesting good repeatability of the sensor. The good repeatability of the sensor could be attributed to the rapid protonation and deprotonation of the PANI chains upon interacting with the water molecules. Besides, the humidity sensor response of the PANI/SLS- $X$ coated paper sensor at different loadings of SLS was also investigated. Furthermore, the sensor showed excellent durability and long term stability (Fig. S2, ESI $\dagger$ ).

The sensor response ( $R \%$ ) was determined using eqn (3) and plotted as a function of relative humidity (Fig. 8). The response of the sensor increased with the increase in the relative humidity level. A slight non-linear response was observed under low relative humidity conditions, which could be attributed to the inadequate response of the sensor. Nevertheless, the sensor displayed good linearity under higher humidity conditions $(>10 \%)$. The linearity value of the PANI/SLS- $X$ based paper sensor was determined by determining the correlation coefficient $\left(R^{2}\right)$ of response $v s$. relative humidity. For PANI/SLS0.0 , a $R^{2}$ value of 0.87 was attained, while it increased to 0.90 , $0.98,0.89$ and 0.78 for $0.125 \mathrm{~g}, 0.25 \mathrm{~g}, 0.50 \mathrm{~g}$ and $0.75 \mathrm{~g}$ of SLS assisted PANI nanorods, respectively.

Sensors with PANI/SLS-0.125 and PANI/SLS-0.25 showed excellent response compared to other configurations. For pure PANI, the response of the sensor was $70 \%$, which increased to $459 \%$ and $588 \%$ for PANI/SLS-0.125 and PANI/SLS-0.25, respectively. A further increase in the SLS loading showed a decrease in the sensor response. The increase in sensor response is attributed to the increase in the absorption of the water molecules, subsequently followed by the augmentation of the charge concentration due to PANI doping. The increase in
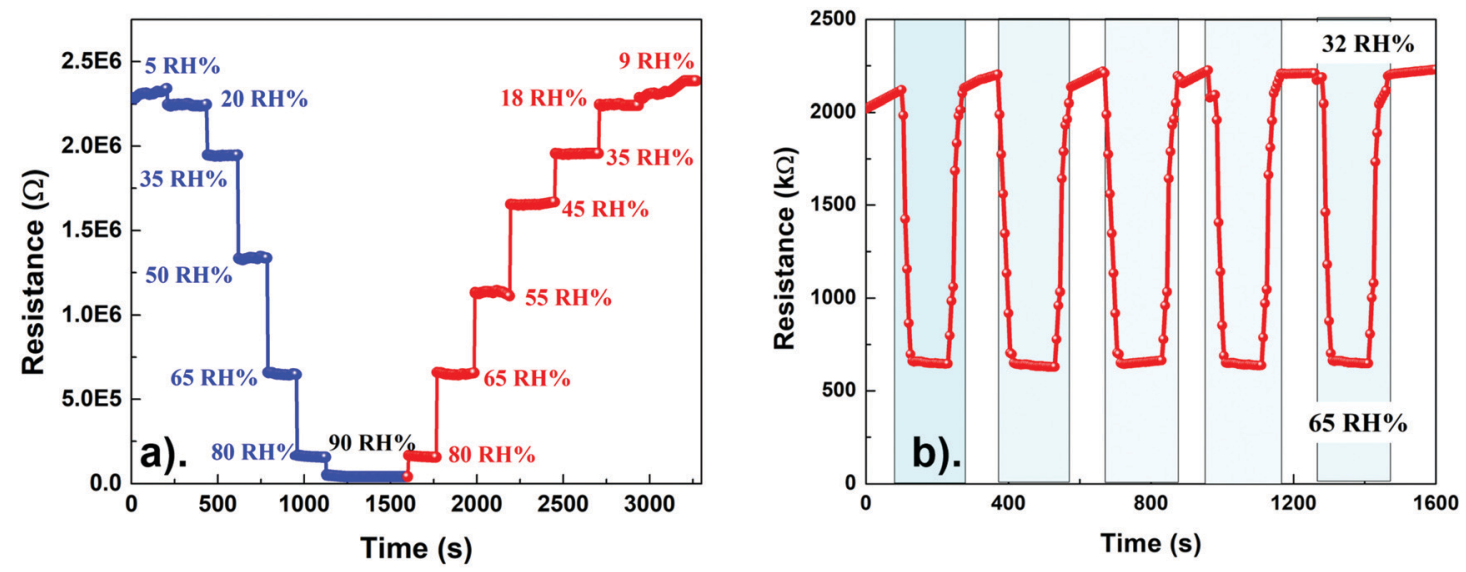

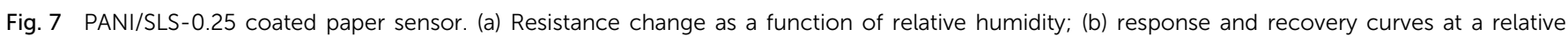
humidity varying from $32 \%$ to $65 \%$. 


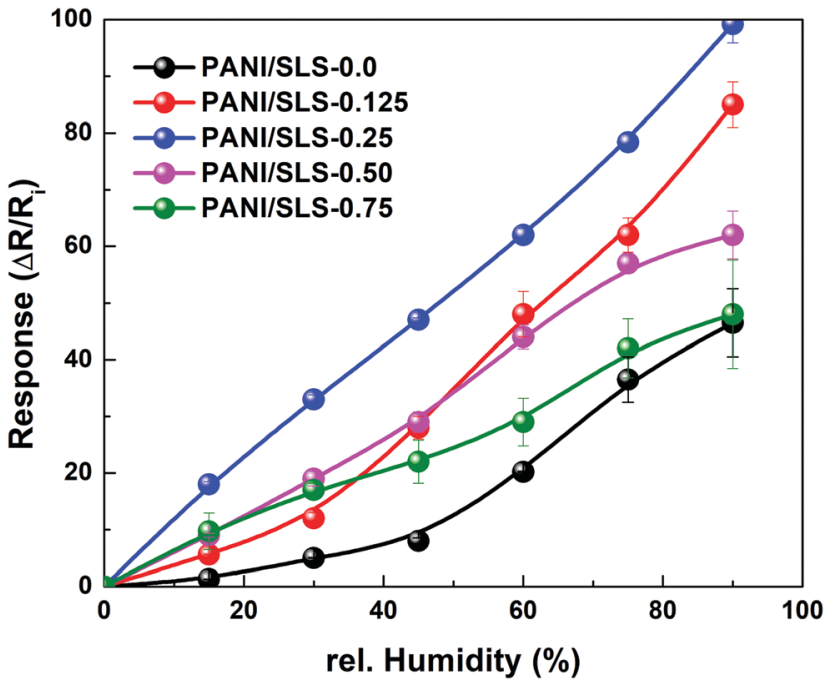

Fig. 8 Response transients of the PANI/SLS- $X$ coated paper sensor as a function of relative humidity.

the response subsequently showed an increase in the sensitivity of the sensor. The highest sensitivity of $31.5 \mathrm{k} \Omega / \mathrm{RH} \%$ was achieved for the PANI/SLS-0.25 based sensor, which was $\sim 6$ fold higher compared with PANI/SLS-0.0. A comparative study with other PANI based humidity sensors was carried out, which depicts the excellent sensing properties of the PANI/SLS coated paper sensor (Table 2).

The emeraldine base form of PANI exists in a partially oxidized form of the structure, which can be protonated due to the unbound electron pair on the N-atom. When the $\mathrm{H}_{2} \mathrm{O}$ molecules interact with the PANI chain, the electrical conductivity increases, attributed to the hopping mechanism. As a result, the electrons moved from the reduced state (protonated) to the oxidized form (eqn (4) and (5)). The $\mathrm{H}_{2} \mathrm{O}$ molecules play an essential role in the process and the reaction of proton transfer to the $\mathrm{H}_{2} \mathrm{O}$ molecules is given in eqn (6). ${ }^{71,72}$ Hence, the hopping of the hydronium ions across the layers of $\mathrm{H}_{2} \mathrm{O}$ molecules is a major cause in the conduction process. Thus, the reaction makes the PANI chains sensitive to humidity conditions. However, this mechanism does not hold good at higher humidity levels ( $>30 \%$ ), which showed a sharp increase in the sensor conductivity.

$$
\begin{gathered}
-\mathrm{NH}-\rightarrow-\mathrm{NH}_{2}- \\
-\mathrm{N}=\rightarrow-\mathrm{NH}^{+}= \\
-\mathrm{NH}_{2}^{+}-+\mathrm{H}_{2} \mathrm{O} \rightarrow-\mathrm{NH}^{+}=+\mathrm{H}_{3} \mathrm{O}^{+}
\end{gathered}
$$

Another possibility is that when the sensor was exposed to low humidity conditions, only a few $\mathrm{H}_{2} \mathrm{O}$ molecules are available to interact with the PANI chains. The $\mathrm{H}_{2} \mathrm{O}$ molecules are chemically absorbed on the activated surface of the PANI chains, which is escorted by the dissociative mechanism of $\mathrm{H}_{2} \mathrm{O}$ molecules to form hydroxyl groups. As a result, the hydroxyl groups of $\mathrm{H}_{2} \mathrm{O}$ molecules adsorbed on metal cations available on the grain surface and provide high charge carrier density and electrostatic regions, thus offering transportable protons. The protons are transferred from one site to another and interact with the neighboring site (oxygen atoms) to form hydroxyl groups. Under low humidity conditions, the adsorption of $\mathrm{H}_{2} \mathrm{O}$ molecules occurs relatively at a lower rate, which ultimately ends up in island-like structures. Thus, the distance between active sites is significant, limiting the migration of the protons leading to low electrical conduction of the sensor. In contrast, at higher humidity levels, a chemisorbed layer is formed and remains stable even after its continuous exposure to humidity conditions. Once the chemical adsorption process is completed, the succeeding $\mathrm{H}_{2} \mathrm{O}$ molecules interact with the chemisorbed layer through the physisorption process to form a hydroxyl multilayer (Fig. 9). Once the second layer is formed, the successive $\mathrm{H}_{2} \mathrm{O}$ molecules adsorb through double hydrogen bonding to two adjacent groups. Further exposure of the sensor to the $\mathrm{H}_{2} \mathrm{O}$ molecules, the monolayer of the physisorption layer stack, forms multiple layers. These layers are less organized than the first physisorption layer and the $\mathrm{H}_{2} \mathrm{O}$ molecules may be singly bonded to local hydrogens. As a result, a large number of molecules are available on the surface; the single-bonded $\mathrm{H}_{2} \mathrm{O}$

\begin{tabular}{|c|c|c|c|c|c|}
\hline Sample & Method & Detection range (\%RH) & Response (\%) & Sensitivity & Ref. \\
\hline PANI/Paper & Rapid mixing and polymerization & $16-96$ & - & $9.79 \mathrm{k} \Omega / \% \mathrm{RH}$ & 62 \\
\hline PANI/PP & In situ polymerization & $0-100$ & 35 & - & 32 \\
\hline $\mathrm{PANI} / \mathrm{TiO}_{2}$ & Spin coating & $10-90$ & 92 & & 20 \\
\hline PANI/ZnO & Spin coating & $5-80$ & 40 & & 22 \\
\hline $\mathrm{NiO} / \mathrm{PANI}$ & In situ polymerization & 5-90 & $\sim 13$ & $7.9 \mathrm{k} \Omega / \% \mathrm{RH}$ & 23 \\
\hline Co/PANI & Dip-coating & 20-95 & & $6 \mathrm{mV} / \% \mathrm{RH}$ & 66 \\
\hline $\mathrm{PANI} / \mathrm{TaS}_{2}$ & In situ polymerization & $10-97$ & 97 & & 67 \\
\hline $\mathrm{PANI} / \mathrm{TiO}_{2}$ & In situ polymerization & $25-95$ & 84 & & 68 \\
\hline $\mathrm{PANI}-\mathrm{Cr}_{2} \mathrm{O}_{3}$ & In situ polymerization & 20-95 & 87 & & 69 \\
\hline Orange dye/PANI & Drop casting & $30-90$ & - & - & 31 \\
\hline PVA/PANI & Sol-gel & $25-90$ & & $12.6 \mathrm{k} \Omega / \% \mathrm{RH}$ & 70 \\
\hline PANI/SLS & In situ polymerization & $5-95$ & 99.2 & $35.1 \mathrm{k} \Omega / \% \mathrm{RH}$ & This study \\
\hline
\end{tabular}
molecules become transportable and able to form unceasing

Table 2 Comparison of the PANI/SLS coated paper sensor with other reported humidity sensors based on PANI 


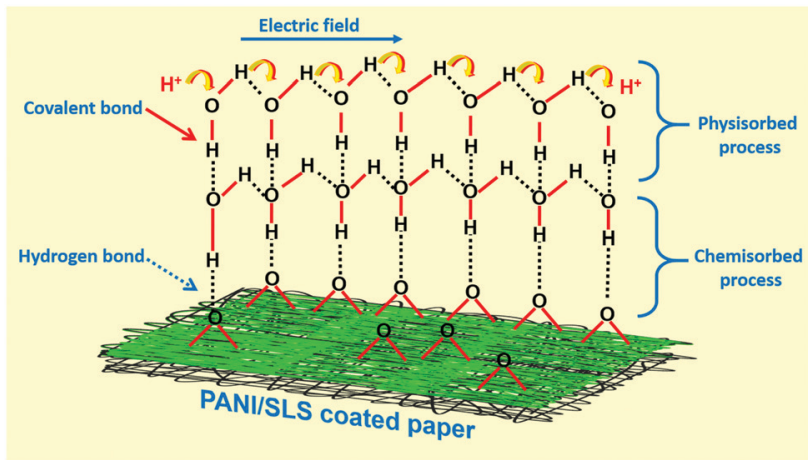

Fig. 9 Plausible mechanism depicting the sensing mechanism of the PANI/SLS- $X$ coated paper sensor.

dipoles and electrolyte layers between the electrodes. Therefore, the sensor sensitivity increased sharply under high humidity conditions due to an upsurge in the conductivity and dielectric constant. $^{32,61,73,74}$

The response of the PANI/SLS coated paper sensor was also investigated under the application of stress (pressure, bending and twisting). As expected, the sensor did not show a significant change in the resistance upon the application of stress (Fig. S3, ESI $\dagger$ ). The insignificant change could be due to the weak stress transfer and poor elasticity of PANI and paper substrates. Also, conductivity change is unreliable due to the poor formation of the conductive network upon the application of pressure.

However, the synthesized PANI can be further explored by stacking the multiple layers of the sensor, which could spontaneously form microstructure air gaps between the layers, forming a conductive network between the layers. Since we have explored
PANI/SLS for humidity sensing performance using a single layer of the sensor, we restricted the investigation to a single sensor layer for pressure sensing. ${ }^{75-77}$ The poor sensitivity of the sensor against different pressure conditions suggests excellent selectivity of the sensor for humidity sensing. High sensitivity, selectivity, repeatability, lightweight, ease of fabrication, improved electrical properties and quick response along with low hysteresis could make the PANI/SLS coated paper sensor a potential material for humidity sensing application.

With the above motivation, we have attempted to explore the humidity sensor for real-time monitoring. Monitoring of respiratory and wearable capabilities could receive widespread attention for the humidity sensor. Since, the respiration process involves a substantial change in the water concentration, the PANI/SLS coated paper sensor could be helpful for respiratory monitoring. Fig. 10a shows the digital photograph of sensor integration on the FFP3 mask (enlarged images showing the integrated sensor and schematic of the arrangement of the sensor). The sensor was covered with an extra layer using a cotton cloth to prevent the sensor from contacting the skin. It also ensures that no loose particles go into the mouth or nose while breathing. During breathing, the temperature of the sensor may vary from $3-5{ }^{\circ} \mathrm{C}$ during the inhaling and exhaling processes. Therefore, we have tested the resistance change of the sensor at different temperatures ranging from $25-40{ }^{\circ} \mathrm{C}$. Interestingly, the sensor exhibited negligible resistance change to varying the temperature from $25-40{ }^{\circ} \mathrm{C}$. As mentioned above, the influence of pressure had a negligible effect on the sensor response. Therefore, we can conclude that the PANI/SLS based paper sensor is highly selective for humidity sensing, which makes it worthy of implementation for the respiration monitoring system. Fig. 10b and c show the response signal of

a.

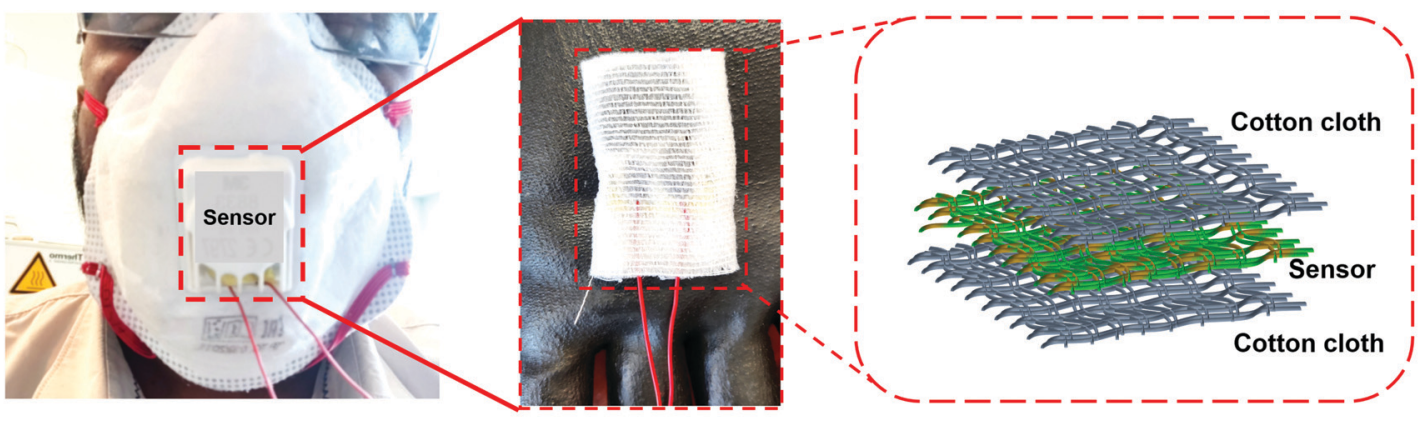

b.

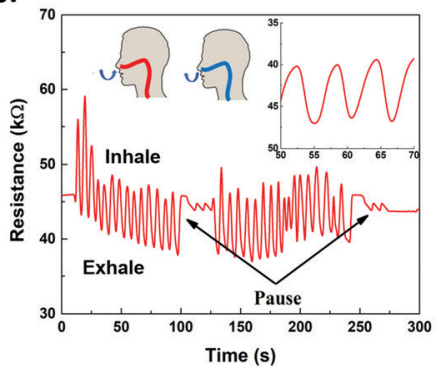

C.

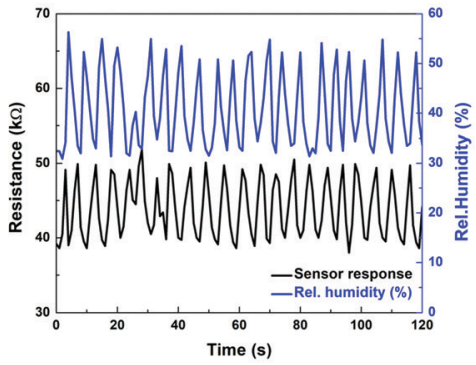

d.

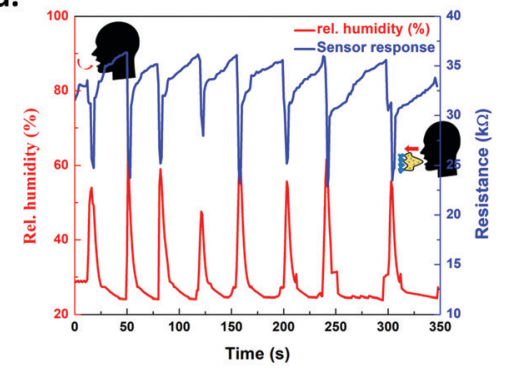

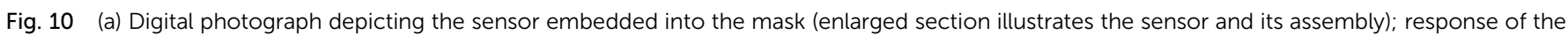
PANI/SLS-0.25 coated paper sensor; (b) normal breathing; (c) deep breathing; and (d) mouth breathing. 


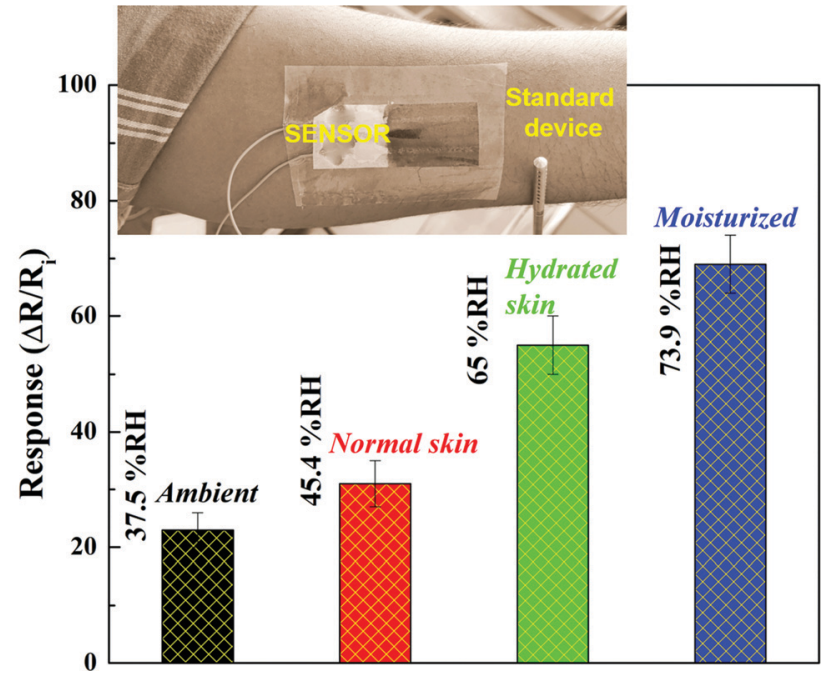

Fig. 11 Variation in response of the PANI/SLS-0.25 coated paper sensor to different skin moisture conditions (inset: sensor attached to the skin onto the human skin).

the PANI/SLS-0.25 based paper sensor for normal breathing (10 breathes per minute) and fast breathing (15 breathes per minute). The sensor exhibited a distinct response for normal and fast breathing. When the volunteer inhales, the resistance increased, while the resistance decreased while exhaling. The sensor showed a peak intensity variation of $29.7 \%$ and $\sim 31 \%$ upon normal and fast breathing. The constant response suggests that the sensor was insensitive against temperature or force exerted due to fast breathing. The sensor showed no response during the apnea, suggesting a distinct response during inhaling, exhaling, and apnea. Furthermore, the sensor was quick to respond and recover without any change in the response.

The response and recovery time were $1 \mathrm{~s}$ and $1.5 \mathrm{~s}$, respectively. The sensor response was also recorded against mouth breathing (Fig. 10d). Interestingly, the nature of the response curve was entirely distinct compared to nose breathing. The sensor responded quickly upon breathing and showed a response of $\sim 41 \%$. The response and recovery time were $1.5 \mathrm{~s}$ and $\sim 10 \mathrm{~s}$. The delay in the recovery of the sensor could be attributed to the slow desorption process due to the presence of a high number of water molecules. The fast response, high sensitivity, excellent selectivity and distinct response of the sensor make it a strong candidate for a real-time respiration monitoring system. On the other hand, the installation of the sensor is relatively simple and does not require heavy equipment for measuring the sensor output. Also, the sensor is relatively thin, flexible and lightweight, thanks to the paper substrate. The PANI/SLS particles are tightly held between the intervenes of the paper fibers and additional protection layers of cotton fabric prevent the particles from breakdown. Moreover, several articles reported the biocompatibility of PANI nanorods, which could be beneficial for practical implementation. ${ }^{78,79}$

The moisture of skin was assessed by attaching the sensor to the skin, which is useful for an individual to monitor their skin condition (inset of Fig. 11). A commercial humidity measuring probe was attached to the skin to monitor the humidity/ moisture variations. The sensor showed distinct response under various humidity conditions (Fig. 11). Upon the application of a moisturizer, the sensor responded readily. The results demonstrate that the PANI/SLS coated paper sensor can be used for predicting the skin moisture. The performance of the PANI/SLS coated paper sensor offers better prospects to utilize it as a multi-functional smart wearable sensor.

\section{Summary and conclusions}

PANI/SLS- $X$ nanorods were synthesized via a solid-state synthesis method. PANI treated with SLS surfactants readily facilitated PANI nanorod formation with smaller diameters than pure PANI nanorods. The electrical conductivity of PANI nanorods was augmented three-fold upon the addition of SLS. The presence of SLS hindered the thermal degradation of PANI nanorods. The PANI/SLS coated paper-based humidity sensor showed excellent response and reproducibility. The PANI/SLS-0.25 composition showed the highest sensitivity of $31.5 \mathrm{k} \Omega / \% \mathrm{RH}$, which is five-fold high compared to pure PANI nanorods. The humidity sensor was further used to demonstrate its applicability by implanting for respiration monitoring and skin moisture detection. The sensor response was distinct and repeatable in different breathing modes. The flexibility, facile synthesis process, high electrical conductivity, and excellent humidity sensor performance and wearable characteristics make it a potential candidate for humidity sensor applications.

\section{Funding details}

This work is a part of "Smarter Leichtbau 4.1" project funded by the European Regional Development Fund (EFRE.) Grant (KWF-5462 | 34039 | 49275).

\section{Author contributions}

J. M.: experiments and data curation; G. W.: software, methodology, investigation; H. L.: conceptualization, supervision, project administration; M. G.: data curation, paper writing review \& editing, supervision.

\section{Conflicts of interest}

The authors declare that they have no known competing financial interests or personal relationships that could have appeared to influence the work reported in this paper.

\section{Acknowledgements}

The authors would like to thank Ms Sandra Jury and Ms Sigrid Steindorfer for carrying out DSC-TGA analysis. The authors are also grateful to Dr Rizawan-ur Rahman (National Institute of Technology, Karnataka, India) for XRD analysis. Finally, MK would like to thank Kompetenzzentrum Holz GmbH, Austria, 
Dr Arunjunairaj Mahendran and Prof. S Anandhan (National Institute of Technology, Karnataka, India) for their continuous support.

\section{References}

1 Y. Pang, J. Jian, T. Tu, Z. Yang, J. Ling, Y. Li, X. Wang, Y. Qiao, H. Tian, Y. Yang and T. L. Ren, Biosens. Bioelectron., 2018, 116, 123-129.

2 C. Zhou, X. Zhang, N. Tang, Y. Fang, H. Zhang and X. Duan, Nanotechnology, 2020, 31, 125302.

3 R. Malik, V. K. Tomer, Y. K. Mishra and L. Lin, Appl. Phys. Rev., 2020, 7, 021301-021399.

4 H. Farahani, R. Wagiran and M. N. Hamidon, Sensors, 2014, 14, 7881-7939.

5 Z. M. Rittersma, Sens. Actuators, A, 2002, 96, 196-210.

6 C. Lv, C. Hu, J. Luo, S. Liu, Y. Qiao, Z. Zhang, J. Song, Y. Shi, J. Cai and A. Watanabe, Nanomaterials, 2019, 9.

7 V. I. Popov, D. V. Nikolaev, V. B. Timofeev, S. A. Smagulova and I. V. Antonova, Nanotechnology, 2017, 28, 1-21.

8 S. Borini, R. White, D. Wei, M. Astley, S. Haque, E. Spigone, N. Harris, J. Kivioja and T. Ryhänen, ACS Nano, 2013, 7, 11166-11173.

9 Y. Zheng, L. Wang, L. Zhao, D. Wang, H. Xu, K. Wang and W. Han, Adv. Mater. Technol., 2021, 6, 1-8.

10 R. P. Tandon, M. R. Tripathy, A. K. Arora and S. Hotchandani, Sens. Actuators, B, 2006, 114, 768-773.

11 B. Deshkulkarni, L. R. Viannie, S. V. Ganachari, N. R. Banapurmath and A. Shettar, IOP Conf. Ser.: Mater. Sci. Eng., 2018, 376, 012063-012072.

12 V. Sridevi and S. Malathi, Chem. Sci. J., 2011, 2, 1-6.

13 M. Maruthapandi, A. Saravanan, J. H. T. Luong and A. Gedanken, J. Funct. Biomater., 2020, 11.

14 R. Suresh, K. Giribabu, R. Manigandan, S. Praveen Kumar, S. Munusamy, S. Muthamizh and V. Narayanan, Anal. Lett., 2016, 49, 269-281.

15 F. Zeng, X. Liu, D. Diamond and K. Tong, Sens. Actuators, B, 2010, 143, 530-534.

16 M. L. Rozemarie, B. Andrei, H. Liliana, R. Cramariuc and O. Cramariuc, IOP Conf. Ser.: Mater. Sci. Eng., 2017, 209, 12063-12073.

17 T. F. Wu and J. D. Hong, RSC Adv., 2016, 6, 96935-96941.

18 G. Liao, Q. Li and Z. Xu, Prog. Org. Coat., 2019, 126, 35-43. 19 S. Manjunatha, B. Chethan, Y. T. Ravikiran and T. Machappa, AIP Conf. Proc., 2018, 1953, 030096-030100.

20 M. Sasikumar and N. P. Subiramaniyam, J. Mater. Sci.: Mater. Electron., 2018, 29, 7099-7106.

21 V. K. Tomer, N. Thangaraj, S. Gahlot and K. Kailasam, Nanoscale, 2016, 8, 19794-19803.

22 S. K. Shukla, V. Khati, Minakshi, A. Bharadavaja, A. Shekhar and A. Tiwari, Adv. Mater. Lett., 2012, 3, 421-425.

23 P. Singh, C. S. Kushwaha, S. K. Shukla and G. C. Dubey, Polym.-Plast. Technol. Mater., 2019, 58, 139-147.

24 A. T. Ramaprasad and V. Rao, Sens. Actuators, B, 2010, 148, 117-125.
25 M. M. Abdi, P. M. Tahir, R. Liyana and R. Javahershenas, Molecules, 2018, 23.

26 S. J. Su and N. Kuramoto, Synth. Met., 2000, 108, 121-126.

27 A. Olad, F. Ilghami and R. Nosrati, Chem. Pap., 2012, 66, 757-764.

28 M. T. S. Chani, K. S. Karimov, F. A. Khalid and S. A. Moiz, Solid State Sci., 2013, 18, 78-82.

29 A. Manaf, M. A. E. Hafizah, A. F. Riyadi and Andreas, J. Phys.: Conf. Ser., 2011, 1153, 012067-012073.

30 D. Kim, J. Choi, J. Y. Kim, Y. K. Han and D. Sohn, Macromolecules, 2002, 35, 5314-5316.

31 M. T. S. Chani, K. S. Karimov, F. A. Khalid, S. Z. Abbas and M. B. Bhatty, Chin. Phys. B, 2013, 22, 010701-010706.

32 P. Cavallo, D. F. Acevedo, M. C. Fuertes, G. J. A. A. Soler-Illia and C. A. Barbero, Sens. Actuators, B, 2015, 210, 574-580.

33 Y. Ma, M. Ma, X. Yin, Q. Shao, N. Lu, Y. Feng, Y. Lu, E. K. Wujcik, X. Mai, C. Wang and Z. Guo, Polymer, 2018, 156, 128-135.

34 Y. Ma, Z. Zhuang, M. Ma, Y. Yang, W. Li, J. lin, M. Dong, S. Wu, T. Ding and Z. Guo, Polymer, 2019, 182, 121808-121816.

35 T. Wang and Y. J. Tan, Corros. Sci., 2006, 48, 2274-2290.

36 B. Qiu, C. Xu, D. Sun, Q. Wang, H. Gu, X. Zhang, B. L. Weeks, J. Hopper, T. C. Ho, Z. Guo and S. Wei, Appl. Surf. Sci., 2015, 334, 7-14.

37 G. Niarchos, G. Dubourg, G. Afroudakis, M. Georgopoulos, V. Tsouti, E. Makarona, V. Crnojevic-Bengin and C. Tsamis, Sensors, 2017, 17, 516-527.

38 J. Zikulnig, M. Khalifa, L. Rauter, H. Lammer and J. Kosel, Chemosensors, 2021, 9, 95-109.

39 R. Cherrington and J. Liang, in Design and Manufacture of Plastic Components for Multifunctionality: Structural Composites, Injection Molding, and 3D Printing, Elsevier Inc., 2016, pp. 19-51.

40 D. A. Tonpe, K. P. Gattu, V. V. Kutwade, M. E. Sonawane, A. S. Dive and R. Sharma, J. Mater. Sci.: Mater. Electron., 2019, 30, 16056-16064.

41 J. Jang and J. Bae, Adv. Funct. Mater., 2005, 15, 1877-1882.

42 X. Bai, X. Li, N. Li, Y. Zuo, L. Wang, J. Li and S. Qiu, Mater. Sci. Eng., C, 2007, 27, 695-699.

43 J. Huang and R. B. Kaner, Chem. Commun., 2006, 367-376. 44 D. Li and R. B. Kaner, J. Mater. Chem., 2007, 17, 2279-2282. 45 Y. Li and X. Jing, React. Funct. Polym., 2009, 69, 797-807.

46 A. Al-Ghamdi and Z. Y. Al-Saigh, J. Chromatogr. A, 2002, 969, 229-243.

47 W. Qiu, L. Ma, M. Gan, J. Yan, S. Zeng, Z. Li and Y. Bai, J. Nanopart. Res., 2014, 16, 2371-2380.

48 T. Jeevananda, H. Siddaramaiah, V. Annadurai and R. Somashekar, J. Appl. Polym. Sci., 2001, 82, 383-388.

49 M. Khalifa and S. Anandhan, ACS Appl. Nano Mater., 2019, 2, 7328-7339.

50 M. I. Boyer, S. Quillard, G. Louarn, G. Froyer and S. Lefrant, J. Phys. Chem. B, 2000, 104, 8952-8961.

51 T. Abdiryim, Z. Xiao-Gang and R. Jamal, Mater. Chem. Phys., 2005, 90, 367-372.

52 T. Abdiryim, A. Ubul, R. Jamal and A. Rahman, Materials, 2012, 5, 1219-1231. 
53 Q. C. Zhang, Y. Y. Zhi, E. J. Hu, J. P. Shen and Q. Shen, J. Polym. Res., 2015, 22, 32-34.

54 A. A. Pud, O. A. Nikolayeva, L. O. Vretik, Y. V. Noskov, N. A. Ogurtsov, O. S. Kruglyak and E. A. Fedorenko, Nanoscale Res. Lett., 2017, 12, 493-504.

55 E. C. Gomes and M. A. S. Oliveira, Am. J. Polym. Sci., 2012, 2, 5-13.

56 H. Zeghioud, S. Lamouri, Y. Mahmoud and T. Hadj-Ali, J. Serb. Chem. Soc., 2015, 80, 1435-1448.

57 M. J. R. Cardoso, M. F. S. Lima and D. M. Lenz, Mater. Res., 2007, 10, 425-429.

58 K. Deb, A. Bera and B. Saha, RSC Adv., 2016, 6, 94795-94802.

59 M. Khalifa, A. Mahendran and S. Anandhan, Polym. Compos., 2019, 40, 1663-1675.

60 W. Wang, F. Yang, C. Chen, L. Zhang, Y. Qin and M. Knez, Adv. Mater. Interfaces, 2017, 4, 1600806-1600823.

61 B. Deshkulkarni, L. R. Viannie, S. V. Ganachari, N. R. Banapurmath and A. Shettar, IOP Conf. Ser.: Mater. Sci. Eng., 2018, 376, 12063-12070.

62 S. S. Sandhu, S. Kumar, S. Augustine, U. Saha, K. Arora, S. Bayan, S. K. Ray, N. K. Puri and B. D. Malhotra, IEEE Sens. J., 2020, 20, 12574-12581.

63 M. Joulazadeh, A. H. Navarchian and M. Niroomand, Adv. Polym. Technol., 2014, 33, 1-10.

64 P. Li, Y. Li, B. Ying and M. Yang, Sens. Actuators, B, 2009, 141, 390-395.

65 Q. Lin, Y. Li and M. Yang, Anal. Chim. Acta, 2012, 748, 73-80. 66 A. Vijayan, M. Fuke, R. Hawaldar, M. Kulkarni, D. Amalnerkar and R. C. Aiyer, Sens. Actuators, B, 2008, 129, 106-112.
67 S. Manjunatha, T. Machappa, Y. T. Ravikiran, B. Chethan and A. Sunilkumar, Phys. B, 2019, 561, 170-178.

68 S. Kotresh, Y. T. Ravikiran, H. G. R. Prakash and S. C. V. Kumari, Nanosyst.: Phys., Chem., Math., 2016, 7, 732-739.

69 K. C. Sajjan, A. S. Roy, A. Parveen and S. Khasim, J. Mater. Sci.: Mater. Electron., 2014, 25, 1237-1243.

70 M. Z. Yang, C. L. Dai and W. Y. Lin, Sensors, 2011, 11, 8143-8151.

71 S. Manjunatha, T. Machappa, Y. T. Ravikiran, B. Chethan and M. Revanasiddappa, Appl. Phys. A: Mater. Sci. Process., 2019, 125, 1-10.

72 H. Farahani, R. Wagiran and M. N. Hamidon, Humidity sensors principle, mechanism, and fabrication technologies: A comprehensive review, Sensors, 2014, 14, 7881-7939.

73 S. Jain, S. Chakane, A. B. Samui, V. N. Krishnamurthy and S. V. Bhoraskar, Sens. Actuators, B, 2003, 96, 124-129.

74 S. C. Nagaraju, A. S. Roy, J. B. P. Kumar, K. R. Anilkumar and G. Ramagopal, J. Eng., 2014, 2014, 925020-925027.

75 S. Kang, V. Pradana Rachim, J. H. Baek, S. Y. Lee and S. M. Park, IEEE Access, 2020, 8, 152105-152115.

76 L. Gao, J. Yu, Y. Li, P. Wang, J. Shu, X. Deng and L. Li, Nanomaterials, 2020, 10, 1-11; M. Pyo and J. Hwang, Synth. Met., 2009, 159, 700-704.

77 M. Pyo and J. H. Hwang, Synth. Met., 2009, 159, 700-704.

78 P. Humpolicek, V. Kasparkova, P. Saha and J. Stejskal, Synth. Met., 2012, 162, 722-727.

79 P. Humpolíček, V. Kašpárková, J. Pacherník, J. Stejskal, P. Bober, Z. Capáková, K. A. Radaszkiewicz, I. Junkar and M. Lehocký, Mater. Sci. Eng., C, 2018, 91, 303-310. 